\title{
REFLECTIONS
}

\section{The Dark Bridal Canopy}

\author{
Jeffrey Borkan, $M D, P b D$
}

Department of Family Medicine, Brown Medical School, Providence, RI

Conflict of interest: none reported

\section{CORRESPONDING AUTHOR}

Jeffrey Borkan, MD, PhD

Department of Family Medicine (Brown)

Memorial Hospital of RI

111 Brewster St

Pawtucket, RI 02860

Jeffrey_Borkan@Brown.edu

\begin{abstract}
Physician narratives in family medicine have the potential to convey the vibrant spirit of our field and provide meaningful insights into disease, illness, suffering, and the nature of healing. They may also complement empirical research, education, and practice through their integrative, expressive nature. This true story depicts a challenge faced by the author while serving as a family physician in a desolate, desert region in Israel's southern Aravah Valley (south of the Dead Sea), where he was privileged to practice for a decade. The episode, a fatal car crash in which a newlywed Druse woman (a member of a secretive sect) was killed, involved much more than just the terse details listed in the emergency log. An example of a family medicine physician-and-self drama, this piece takes the reader beyond the basic medical facts into the experience and sensations of the event. It also provides a stark contrast to the usual medical description and emphasizes the importance of stories as reflective opportunities for improving health care, sustaining ourselves as practitioners, and maintaining the vitality of our field.
\end{abstract}

Ann Fam Med 2006;4:75-78. DOI: 10.1370/afm.372.

$\mathrm{S}$ he was beautiful in the illuminated glow of the floodlights, as she had been a few days before under her bridal canopy, with streaming blondish brown hair, high cheekbones, skillfully applied makeup around finely sculpted features, and the fine curvature that would turn any eye. A Druse woman in her early 20s, she was a member of a secret religious sect that had broken from Islam 500 years earlier and, after persistent persecution, had sought refuge in the hilly sections of the Galilee. The large diamond ring that adorned her hand bespoke of her new status as wife, likely to the son of a leading family in her village.

Only now she was not breathing.

I sat crouched near her head on the empty road, the resuscitator bag slowly expanding and emptying in my hands, matching the rising and falling of her chest. The silent desert night moon rose overhead in the cloudless sky, sketching the outlines of mountains on either side of the Aravah Valley. I huddled wordlessly, working intently to revive the woman, as her new husband quietly whimpered some meters away. I had been called from my isolated kibbutz a few kilometers down the road as I was putting the kids to sleep. I raced, if one can do that in a Subaru Justy, up the road upon hearing the news of a reported severe accident. It had been pitch black, save for the lights of my car and the endless canopy of stars on this warm fall night. When I arrived, she already lay on her back on the asphalt, having been pulled from the wreckage. Soon thereafter, one of my nurses arrived on the scene, along with the ambulance and its driver. We were joined some minutes later by an army doctor, an anesthesiologist in civilian life, who had been on his way to reserve duty at a nearby desert army base. Driving late at night from the north after his shift, he had come across the accident and stopped to help.

The couple had been returning from their honeymoon in Eilat, the Miami Beach of Israel, the place of luxurious abandon and celebration. Their first kisses and touches still fresh, they had sped back toward their 
village and their new home among the rocks and scraggy trees of the Galilean hills. The car had not quite made it around this one curve, had probably caught on the soft sand shoulder and flipped. Had they been talking about their future, their love, their new discovery of each other?

$\mathrm{ABC}$ - airway $\mathrm{OK}$, breathing absent, pulse thready, but present, her blood pressure was barely palpable, her body warm. We began CPR, cut away her constricting clothing, and placed line after line, trying to resuscitate with IV fluids the spaces where her blood should have been flowing. The regional civil administrator, who quarreled with me at every chance, save at such critical times, brought in the newly acquired mobile floodlights and illuminated our surreal scene. We worked in the middle of the road, the blacktop still warm from the departed desert sun. Our efforts raged on and on-fluids, drugs, intubation, compressions; nothing changed for the better. The thready pulse disappeared. Think! ABCDE or Scoop and Run, Scoop and Run!! But to where? We were more than an hour from the nearest hospital by ambulance, and calling a helicopter would take even longer.

The husband asked the ambulance driver, who was bandaging his small head wound with long rolls of white gauze, whether his wife was OK. He had been united with her days earlier after all his male relatives had taken him joyfully through the village, accompanied by drums, singing, and dancing to the wedding canopy, while the women and girls of the village had prepared his betrothed meticulously and lovingly for the moment of her vows: "I am my beloved and my beloved is mine." Now from the side of the road the husband looked toward us; we avoided his eyes.

The army doctor and I conferred, I hoped he knew what to do now. We tried a few more resuscitative maneuvers and waited. No response. We stopped talking, continuing CPR against hope, against the wisdom of the books and our teachers.

Time spread out and slowed to a trickle. The road was quiet save for the deep whirring sound of the floodlights generator and the peaceful whoosh of the resuscitator. How beautiful is the desert wind and vista at night: all around us the parched desert browns, grey, and black of the valley, mountains, and sky, save for the inestimable stars, her pale skin, and open green eyes. The army doctor raised his gaze from the woman and said, "All is done." I looked at his somber expression and nodded without comment or outward show of emotion. We stopped, covered her body with a blanket, not thinking to close her eyes. I went to the side of the road as she was placed on the stretcher and into the ambulance. I am unsure whether I spoke to the husband, unsure of whether I filled out the accident report or let it go, or even what I had felt. Had I risen without sentiment, detached, or had I cried over the loss of life, promise, and my failed efforts?

The husband likely returned to his village, his honeymoon turned into a funerary march. The Druse believe in reincarnation, where another generation takes over from the last. Perhaps a child was born with the wife's soul somewhere that night. Perhaps her spirit will have a different journey in the next life, one that would not end so soon in the desert.

After some minutes, I slid into my car and drove back into the enveloping darkness toward my home. The community of 300 was dark when I returned, except for the spotlights surrounding the perimeter fence, a few communal buildings, and the cowsheds. When I reached my doorstep, I listened for chatter, but my wife and children were asleep, breathing softly and assuredly. I shed my bloodied clothing at the door and left it in a pile on the porch. Then I bathed long and hard-feebly attempting to clean off the pale of death-had a glass of wine, said a blessing on each of my children, and fell into a troubled sleep. Reflection could come later.

\section{EPILOGUE: WHAT'S THE POINT OF THE STORY? NARRATIVES IN FAMILY MEDICINE}

Emergency services log, October 12, 1999. A 22-year-old female, non-seat-belted forward passenger in a single-vebicle accident, unresponsive at scene, pronounced dead at 12:37 PM after unsuccessful resuscitation, internal bleeding, cardiopulmonary collapse, and possible bead injuries.

The story, "The Dark Bridal Canopy," could have been written in the usual terse medical vernacular. The text of the emergency $\log$, however, cannot begin to capture the emotions, the sights, or the sounds of that night: the woman's beauty and the quiet magnificence of the desert scene contrasted with the death on the roadway, the lost promise of the couple's life together, and our futile efforts at resuscitation-all surreally illuminated by the portable spotlights. The story above expands beyond the basic medical facts into the experience of the event, creating an opportunity for reflection, mindful practice ${ }^{1}{ }^{1}$ and self-healing. For me, this story is highly personal and stands out from among the myriad of narratives that have been accumulated during the course of 2 decades of family medicine. Several factors are responsible, perhaps foremost being the narrative's ability to exemplify elements of the complex role of a solo family physician in a remote area: the actor and witness to the struggles of life, woven into the framework of pristine natural splendor, communal cohesion, cultural diversity, and my own developing professional and family identity.

Narratives have a central and time-honored place in family medicine, ${ }^{2,3}$ yet it is easy to shunt them aside 
in the face of the pressures posed by rapid-paced, technologically-focused, contemporary health care. The need to consider the story has multiple benefits, however, and may even be considered a medical necessity. As Charon has noted ${ }^{4}$ "The effective practice of medicine requires narrative competence, that is, the ability to acknowledge, absorb, interpret, and act on the stories and plight of others." Physicians, when they do tell stories, have often been willing to describe the patient's illness experience, while being more reticent to delve into their own roles and deliberations. ${ }^{5}$ Stories, such as the one presented in this issue of the Annals of Family Medicine, have the potential to further incorporate reflection into our professional lives and to enrich our field's clinical, educational, and research endeavors.

Making sense of stories may be best approached from a meaning-centered framework. Medical narratives can be categorized or classified in numerous manners, though certain taxonomic elements, such as narrative situation, ${ }_{1}^{4}$ narrative structure, ${ }^{5}$ and visit type, ${ }^{6}$ possibly have the most resonance with our field. The 4 central narrative situations in medicine, according to Charon, ${ }^{4}$ are physician and patient, physician and self, physician and colleagues, and physician and society. These basically expound on the context and frame on which and through which the story takes place. Frank ${ }^{7}$ believes that there are 3 recognizable narrative structures for the stories told by those who are "deeply" ill, or by extension, by those who care for them. These structures provide the skeleton on which stories of illness can be fleshed out and include:

Restitution stories- the preferred narrative type in North America, in which a person becomes ill, is treated, and through this treatment, is restored to health and wellness. During this progression from disease to healing, the wrong is made right, and the physician often emerges as hero.

Chaos story-the diametrical opposite of the restitution story. In chaos stories, deepest illness never remits; rather it only increases in terms of disability and pain, and there is no apparent order or answers in the whirlpool of suffering

Quest story-the illness becomes a condition from which something can be learned. Though healing and restitution may be impossible, illness can be lived as a quest in which learning and transcendence are the result of the journey (either for the patient, the physician, or those around them).

Miller ${ }^{6}$ divides family medicine encounter types into routines, ceremonies, and dramas. Routines are the everyday, limited, acute patient complaints, such as pharyngitis, that can be treated quickly and generate few overarching concerns. Ceremonies, often associated with chronic illness or well visits (eg, prevention or pregnancy), are ritualized encounters that have choreographed patterns. Dramas are the practice stoppers, such as suicide attempts or active angina pectoris, that demand all other scheduled activities to cease.

These approaches can be applied to "The Dark Bridal Canopy." In terms of Charon's narrative situations, the story is an example of a physician-and-self narrative. Physicians are shaped on the anvil of their patients' experiences and their responses to it. Their ability to respond to and reflect on pain, suffering, illness, courage, and hope may be critical to effective diagnosis and treatment. As Novack et al and others have concluded, the physician's most potent therapeutic tool may be the reflective self, attuned to the patient through engagement, compassion, and personal awareness. ${ }^{1,4,8}$ Regarding Frank's taxonomy of narrative structure, "The Dark Bridal Canopy" might be best characterized as a modified chaos story: the patient's suffering, disability, and pain will never remit, and the physician is unable to treat the problems successfully. In general, Western culture, including the culture of Western medicine, fears the chaos narrative because it focuses on the multiplication of troubles brought about by illness and reminds us "how thin the ice is that we skate upon, and how cold and deep is the water we can suddenly sink into." ${ }^{15}$ The modification in the current story is that the narrative is about the chaos, where the physician, through reflection, has found some meaning in the events. This transition nudges it toward the category of the quest story, in which not only can something be learned, but also these insights can be passed on to others.

Clearly, our patients are not the only ones who are in need of finding transcendent or transformative meaning in suffering and death. This need is also acute among the wounded healers who, like myself, are trying to make sense of our own limitations and experiences Insights and reflection on events, as evidenced in the story related here, can help physicians come to terms with the suffering they encounter and provide meaning to their professional roles, even in the face of defeat. In regard to Millers' taxonomy, this story clearly chronicles a drama. It is the kind of event that shatters the daily flow and raises the stakes for both physician and patient. All the participants in the drama, from the couple, to the physicians, nurse, regional administrator, policeman, and ambulance driver, are actors caught in a scene in which neither the timing nor the outcome can be predicted. Dramas need not always be life-threatening, but by their nature they require the full attention, energy, and ability of the practitioner. Their impact on all parties may be longstanding, and their repercussions permanent.

After this incident, I continued my years of work as a country doctor: an actor, observer, and chronicler 
of first breaths, last breaths, and those in-between. I served as a participant in the routines, ceremonies, and dramas of health, sickness, and healing. Sometimes I made a difference, sometimes not ${ }_{i}$ however, like most family physicians, I fulfilled a critical part of my role by just being there, serving as a human witness, a clerk of records, for individuals, families, and communities. Through recording stories such as this one, I took on an oft-undervalued role of the family physician-that of witness and holder of communal memory. ${ }^{9}$

For me and hopefully for the reader, this story provides an opportunity for reflection and self-awareness-key tasks for good clinical practice, ${ }^{1}$ potentially critical to both sustaining ourselves as practitioners and maintaining the vitality of our field. There is so much more to family medicine than the raw facts of particular events or the statistics of our practices or practice patterns. Such stories may capture some of the intangible sights, sounds, and emotions of our work, allowing us to convey the experience and vibrancy of our discipline and provide meaningful insights into disease, illness, suffering, and the nature of healing. This has the potential to be effective for attracting to family medicine everyone from the general public to medical students preparing for their specialty choices and provides a medium for transmitting our wisdom to this and the next generation. Narratives may also complement empirical research, education, and practice through their integrative, expressive nature. Perhaps the ultimate goal is to learn how to incorporate the insights from narrative and narrative reflection into improving the clinical methods, as some have begun to accomplish. ${ }^{10}$ Whether we aim to change health care or just provide a record of our acts, stories may provide a mechanism for finding meaning, sustaining ourselves, and furthering our professional roles and that of our field.
To read or post commentaries in response to this article, see it online at http://www.annfammed.org/cgi/content/full/4/1/75.

Key words: Family practice; communication; narrative medicine; mindfulness; emergency medicine; delivery of health care

Submitted November 11, 2004; submitted, revised, May 9, 2005; accepted May 15, 2005.

Acknowledgements: An earlier version of this story won the 2002 Creative Writing Award for the Best Short Story by the Society of Teachers of Family Medicine (Northeast Regional and Board of Trustees of the Family Medicine Education Consortium). Thanks also go to members of the Brown Family Medicine Writers Group, who provided insightful comments.

\section{References}

1. Epstein RM. Mindful practice. JAMA. 1999;282:833-839.

2. Borkan J, Reis S, Steinmetz D, Medalie JH, eds. Patient and Doctors: Life-Changing Stories from Primary Care. Madison, Wis: The University of Wisconsin Press; 1999.

3. Borkan J, Reis S, Medalie J. Narratives in family medicine: tales of transformation, points of breakthrough for family physicians. Fam Sys Health. 2001;19:121-134

4. Charon R. The patient-physician relationship. Narrative medicine: a model for empathy, reflection, profession, and trust. JAMA. 2001;286:1897-1902.

5. Kleinman A. The Illness Narratives: Suffering, Healing and the Human Condition. Basic Books Inc; 1988.

6. Miller WL. Routine, ceremony, or drama: an exploratory field study of the primary care clinical encounter. J Fam Pract. 1992;34:289-296.

7. Frank A. Just listening: narrative and deep illness. Fam Syst Health. 16:197-212; 1998.

8. Novak DH, Suchman AL, Clark W, et al. Calibrating the physician. Personal awareness and effective patient care. Working Group on Promoting Physician Personal Awareness, American Academy on Physician and Patient. JAMA. 1997; 278:502-509.

9. Hurwitz B. Dead notes: a meditation and an investigation in general practice. In: Greenhalgh T, Hurwitz B, eds. Narrative Based Medicine. Tavistock Square, London: BMJ Books, BMA House; 1998.

10. Greenhalgh T, Collard A, Begum N. Sharing stories: complex intervention for diabetes education in minority ethnic groups who do not speak English. BMJ. 2005;330:628. 